\title{
Complications of bone transport technique using the llizarov method in the lower extremity: a retrospective analysis of 282 consecutive cases over 10 years
}

\section{Yanshi Liu}

Xinjiang Medical University Affiliated First Hospital

\section{Maimaiaili Yushan}

Xinjiang Medical University Affiliated First Hospital

Zhenhui Liu

Xinjiang Medical University Affiliated First Hospital

Jialin Liu

Xinjiang Medical University Affiliated First Hospital

Chuang Ma (D8212682@qq.com)

Xinjiang Medical University Affiliated First Hospital

Yusufu Ahemaitijiang ( $\nabla$ ahmatjang@163.com )

Xinjiang Medical University Affiliated First Hospital

\section{Research article}

Keywords: Bone defect, Bone transport, Complication, External fixation

Posted Date: March 26th, 2020

DOI: https://doi.org/10.21203/rs.3.rs-19335/v1

License: (c) (i) This work is licensed under a Creative Commons Attribution 4.0 International License.

Read Full License

Version of Record: A version of this preprint was published at BMC Musculoskeletal Disorders on June 6th, 2020. See the published version at https://doi.org/10.1186/s12891-020-03335-w. 


\section{Abstract}

Background: The treatment of large bone defects in lower limbs is a serious challenge for orthopedic surgeons and patients. The bone transport technique according to the llizarov method characterized with versatile abilities and has become the main option for the reconstruction of bone defect. However, inevitable difficulties as complications related to bone transport technique have been reported by many studies. Complications which could affect on the clinical outcomes remain a major concern. The purpose of this study was to evaluate the effectiveness and complications of bone transport technique using llizarov method in the treatment of bone defect in lower extremity.

Methods: The study was conducted on 282 patients who underwent bone transport procedures using Ilizarov method at our institution from January 2007 to June 2017. Patient's demographic data, complications and clinical outcomes at two years follow-up were collected and retrospectively analyzed. All difficulties that related to bone transport were documented according to Paley's classification. The clinical outcomes were evaluated using Association for the Study and Application of the Method of llizarov criteria (ASAMI) at last clinical visit.

Results: There were 243 male and 39 females with a mean age of 40 years (range 18-65 years). The mean defect was $6.56 \pm 2.15 \mathrm{~cm}$, whereas single level transport in 221 cases and double level transport in 61 cases. A total of 189 problems, 166 obstacles and 406 complications (257 minor and 149 major complications) were observed $₫$ the average complication rate per patients consists of 0.91 minor and 0.53 major complications. The top five complications were pin-site infection (65.96\%), axial deviation (40.78\%), joint stiffness (23.76\%), soft tissue incarceration $(22.34 \%)$ and delayed union of the docking site (13.48\%). The ASAMI bony result was excellent in 233 patients, good in 32, fair in 5 and poor in 12. The ASAMI functional result was excellent in 136 patients, good in 88, fair in 47, poor in 11 and failure in 0 .

Conclusion: Bone transport is a reliable method for reconstruction of bone defects in the femur and tibia caused by variety of reasons. Particular attention, patient's compliance and experience of the surgeon contribute the satisfactory results.

\section{Background}

The treatment of large bone defects caused by trauma, developmental deformities, resection of tumor or osteomyelitis in lower limbs is a serious challenge for orthopedic surgeons and patients ${ }^{1,2}$. Many surgical procedures have been proposed for the treatment of bone defect ${ }^{3-6}$, and bone transport technique according to the llizarov method is widely practiced in reconstructive surgery ${ }^{7-10}$. The llizarov method is based on the biology of the bone and the ability of the surrounding soft tissues to regenerate under tension stress, so it become the main treatment option for the reconstruction of bone defect, because of the method is characterized by rapid, simple, effective, minimally invasive and fixated reliably, which can preserve the biomechanical microenvironment needed for fracture healing ${ }^{9,11-14}$. 
Although the treatment of bone defect using bone transport technique has been used widely include reconstruction of the bone defect along with soft-tissue coverage, correction of the joint contractures or malalignment. However, inevitable difficulties as complications related to bone transport technique using the llizarov method have been reported by many studies ${ }^{9,13-19}$. It is remaining a major concern to these complications which could affect on the clinical outcomes.

Therefore, the purpose of our study was to evaluate and retrospectively analyze the bone transportrelated complications of patients in our institution over the past 10 years in order to predict the risk of complications and related factors.

\section{Methods}

\section{Patients}

This retrospectively study included 282 patients who underwent bone transport procedures in lower extremity using the llizarov method at our institution from Jan 2007 to June 2017, including 243 male and 39 females with a mean age of 40 years (range 18-65 years). Patients older than 18 years with bone defect more than $3 \mathrm{~cm}$ in the lower extremity and received bone transport procedure using the llizarov method were included. Patients with bone defect caused by pathological fractures, associated vascular and nerve injury, age $>65$ years, poor compliance, and any other illness that can affect bone healing (such as diabetes, hypertension, osteoporosis, kidney disease, etc.) were excluded. This study was approved by the Ethical Committee of our institution.

\section{Surgical technique}

Surgical treatment started by radical debridement. We resected the devitalized or infected bone segments by using an oscillating saw according to the limit of healthy bleeding bone. Cortical bleeding with the tourniquet deflated, described as the so-called paprika sign, was accepted as an indication of vital tissue $^{20}$. In addition, the infected or necrotic soft tissues, especially the sinus tracts, were all debrided adequately. The debridement of bone and soft tissues might perform several times if needed, just keep the residual bony ends flat for better healing. At least 6 samples were taken to culture during operation for all patients. If there was a soft tissue defect, surgical intervention was performed with flap transfer or free skin grafting after infection controlled.

Bone transport was performed when clinical manifestations and laboratory indicators showed there is no infection. Preoperative anteroposterior and lateral X-rays were used to evaluate the defect size and plan the construction of the external fixator. The type of external fixator was comprehensive determined by the location of bone defect and patients' opinion. We conducted bone transport by a minimally invasive osteotomy at the proper site using Gigli saw technique and care was given to preserving as much periosteum as possible. Bone defect which larger than $8 \mathrm{~cm}$ or exceeded $40 \%$ of the injured bone underwent a double level bone transport ${ }^{21-23}$ procedure. All the procedures were conducted by the same surgical team. 


\section{Data collection}

The demographic data include age, sex, weight and height $\left(\mathrm{BMI}=\right.$ weight $\left.(\mathrm{kg}) / \mathrm{height}\left(\mathrm{m}^{2}\right)\right)$, injured bone, location of bone defect (proximal, middle and distal), defect size(DS), type of external fixation (circular (TrueLok Ring Fixation System, Orthofix, Verona, Italy) or monolateral (Limb Reconstruction System, LRS, Orthofix, Verona, Italy)), type of bone transport (single level and double level), direction of bone transport(from proximal to distal or distal to proximal in single level and converging or "twin" transport in double level) were collected.

Postoperative data were recorded which include distraction regenerate length (DRL), docking time (DT), regenerate consolidation time (CT), external fixation time (EFT), external fixation index (EFI) and type of difficulties occurred during and after bone transport procedure. The EFT referred to the time spend on before removal of the external fixator. The EFI was defined as the ratio of the days of EFT to the DRL (centimeters). Radiographic evaluation was conducted every 2 weeks during the bone transport period and every month in the consolidation phase. All patients were closely followed up at minimum of two years after the removal of external fixator (EF).

According to Paley ${ }^{24}$, difficulties that occur during limb lengthening were subclassified into problems, obstacles and complications. Problems represented difficulties that required no operative intervention to resolve, while obstacles represented difficulties that required an operative intervention. All intraoperative injuries were considered true complications, and all problems during limb lengthening that were not resolved before the end of treatment were considered true complications. True complications were subclassified as minor and major complications. Minor complications did not affect the final result or required nonoperative or a minor operative intervention, while major complications required a more complex and unplanned operative intervention or resulted in permanent sequelae. The bone and functional results were assessed by $\mathrm{ASAMI}^{21}$ at the last clinical visit.

\section{Postoperative management}

All patients were encouraged to do isometric muscle and joint range of motion (ROM) exercise within the tolerance of pain on the second day after surgery. Antibiotics that are suitable according to the results of cultures and antibiotic susceptibility tests are applied intravenously for at least 3 weeks or until the erythrocyte sedimentation rate (ESR) and C-reactive protein (CRP) levels return to normal limits.

According to the reference data 25,26 , after latency period of 7 to 10 days, bone transport started at a rate of $1 \mathrm{~mm}$ (single level) or $2 \mathrm{~mm}$ (double level) daily, 4 times a day. The rate of bone transport was adjusted according to patients' tolerance and the quality of the regenerate. The procedure of bone transport continued for 4 or 5 days to compress the docking site after the docking. The external fixator was dynamized before removal. And removal of the external fixator was conducted when the standard orthogonal radiographs showed sufficient consolidation of the distraction zone (dense bone formation) and solid docking site union (corticalization in 3 of 4 cortices). Additionally, all patients were put on the functional brace for 4-6 weeks for the protection of refracture 


\section{Statistical analysis}

Statistical analysis was performed with the SPSS 22.0 (IBM Corp, USA) and R Studio (Version 1.2.5001) with rms, ROCR, gplots and forest plot packages. Continuous variables were analyzed by Independentsamples $T$ tests and expressed as the mean and standard deviation. And the count variables were analyzed by the Chi-square or Fisher's test, expressing as number. Statistically significant difference was set at $P<0.05$.

Variables with $P<0.05$ were identified in the univariate logistic regression analysis (ULRA). And the variables with $P<0.1$ in the ULRA were included in the multivariate logistic regression analysis (MLRA), then variables with $P<0.05$ were screened out by the stepwise method and these variables were used to construct the nomograms. Finally, the ability of nomograms to distinguish the models was evaluated by the area under the curve (AUC) of the receiver operating characteristic (ROC) curve.

\section{Results}

The etiology of bone defect include posttraumatic in 97 cases (17 femur and 80 tibias), osteomyelitis in 146 (31 femurs and 115 tibias), infected nonunion in 26 ( 11 femurs and 15 tibias) and atrophic nonunion in 13 ( 3 femurs and 10 tibias). A total of 220 tibial and 62 femoral bone transport procedures in our study were collected. The llizarov circular fixator was applied in 128 cases (all in tibia), and the monolateral fixator was applied in 154 cases (62 femurs,92 tibias). The average DS was $6.56 \pm 2.15 \mathrm{~cm}$ (range 3 to 14 $\mathrm{cm}$ ). Based on the bone defect location, proximal 1/3 of the diaphysis in 32 cases (4 in femur, 28 in tibia), middle 1/3 in 129 (31 in femur, 98 in tibia) and distal 1/3 in 121 cases ( 27 in femur, 94 in tibia). A total of 221 cases underwent single level bone transport procedure and 61 cases were treated by double level bone transport.

The differences of DS, DT, CT, EFT and EFI between single level and double level were statistically significant $(p<0.05)$, whereas they were not statistically significant in the same level $(p>0.05)$. The mean EFI in the double level group is lower than that in the single level group. More details are shown in Table1-3.

Based on the ASAMI scoring, bony result was excellent in 233 patients (82.62\%), good in 32(11.35\%), fair in $5(1.77 \%)$, poor in $12(4.26 \%)$. The functional result was excellent in 136 patients (48.23\%), good in 88 (31.21\%), fair in $47(16.67 \%)$, poor in $11(3.90 \%)$, failure in 0 (Table 4$)$.

There were 189 problems, 166 obstacles and 406 complications ( 257 minor complications and 149 major complications) in our study (Table 5), the average complication rate per patients consists of 0.91 minor and 0.53 major complications (Table 6).

The top five complications of our study were pin-site infection (65.96\%), axial deviation (40.78\%), joint stiffness (23.76\%), soft tissue incarceration (22.34\%) and delayed union of the docking site (13.48\%) (Table 6). Pin tract infection was occurred in most of the patients and managed by daily pin site care and oral antibiotics, 60 patients suffered deep pin tract infection or pin loosening and successfully treated by 
pin replacement and intravenous antibiotics. Axial deviation occurred in 115 patients, modification of the apparatus or inserting an additional Schanz screw(s) to pull the bone out of its deviated position was required before the end of the treatment. Joint stiffness occurred in 67 cases and treated with physiotherapy along with joint release if needed. Soft tissue incarceration was noted in 63 cases and managed by freshening the bone ends, opening the medullary canal and resection of invaginated softtissue. Delayed union was presented in 38 cases and treated by "accordian" technique or bone grafting if it was developed to nonunion.

For the top five complications, we analyzed those with the related factors by ULRA, MLRA, nomogram and AUC, the details are shown in Figure1-5. It is generally believed that the model with AUC of 0.50-0.75 is acceptable, and our results are all in this range.

\section{Discussion}

Our results showed that double level bone transport can greatly shorten the treatment time compared with single level bone transport. In previous studies ${ }^{27-31}$, the mean EFI was 50.0 days/cm (range 43.1 to 58.1 days $/ \mathrm{cm}$ ) in patients treated by single level bone transport, and it is lower than that in our study $(66.54 \pm 8.58$ days $/ \mathrm{cm})$. This can be explained by the mechanism of bone defect in our study is mostly caused by posttraumatic osteomyelitis (51.77\%) which requires repeated debridement before the initiation of bone transport, the microenvironment for bone regeneration and soft-tissue coverage may destructed, both docking union and regenerate maturation become time consuming process.

The majority of patients had suffered from various complications during the long treatment period 24,32 , 33. In the Paley and Maar's study ${ }^{34}, 19$ patients with tibial bone defects were treated with bone transport by llizarov method, union was achieved in all cases but 22 minor and 19 major complications were observed, the mean complication rate per patient was 1.15 minor and 1.00 major complications. As for Spieql $\mathrm{U}$ et al ${ }^{9}$, total of 25 patients were included in their study, the patients suffered 22 minor and 13 major complications, and the average complication rate consists of 0.88 minor and 0.52 major complications per patients. Other authors also reported high complication rates in the bone transport procedure ${ }^{27,30}$. Complications were more prevalent in the single level group (329 complications of 221 patients), whilst it was less in the double level group (77 complications of 61 patients) in the present study due to shorter treatment course.

\section{Pin track problems}

ULRA showed that the presence of pin track problems is less in patient with less BMI, smaller defect size in tibia, shorter CT, ET and EFI. It is due to less soft coverage of tibia in thin patient and shorter time spent in external fixator can significantly reduce the occurrence of pin track problem.

The result of the MLRA showed that less occurrence of pin tract problem in younger patients with smaller tibial defect. Immune system is stronger with better elasticity of local soft tissue in younger patient 
compared with older one. Besides, more resistance was encounter due to abundant muscle coverage in femur than tibia which can explain the higher occurrence of pin tract problem in femoral bone transport than tibia.

\section{Axial deviation}

ULRA showed that younger people with bone defect located in the middle $1 / 3$ of tibia suffered less probability of axial deviation. This can be explained by stability of pins are stronger in younger patients (less occurrence of osteoporosis compared with older patient) and muscle tension have less effect in middle $1 / 3$ bone defect during bone transport. The possibility of axial deviation is also less in cases with smaller defect size and shorter DT, CT, ET and EFI which is consisted with the generally accepted theory, the stability of external fixator will be reduced with longer time spend on fixator mountain. The MLRA demonstrated that younger patient, tibial defect, shorter DT and EFI are related with less probability of axial deviation.

\section{Joint stiffness}

ULRA showed that older people with larger femoral defect using double level bone transport tend to have joint stiffness. Additionally, longer EFI lead to prolonged fixation time and patient may reluctant to perform functional exercise which may increase the chance of joint stiffness. As for ASAMI score, the fair and poor grade were not clinically significant. Aforementioned result was also found in the MLRA. Isometric muscle and joint range of motion (ROM) exercise within the tolerance of pain on the second day after surgery is strongly recommended to prevent the occurrence of joint stiffness.

\section{Delayed union}

Both ULRA and MLRA showed that delayed union is more likely to occur in patient with large defect size, longer docking time and EFI. The bone end become ossified due to microvascular occlusion before contact with longer docking time. Moreover, improper application of the external fixator or poor alignment may alter the biomechanical environment required by bone union, in addition, less functional exercise causes less physiological stress stimulation on the bone end, all of these factors contributed to the occurrence of delayed union.

\section{Soft tissue incarceration}

ULRA showed that patient with smaller femoral defect using double level "twin" bone transport is less likely to suffer soft tissue incarceration. Additionally, longer DT and ET also increase the chance of soft tissue incarceration. The result of MLRA demonstrated that only DT is significantly associated with the occurrence of soft tissue incarceration.

In our study, we used ASAMI score to evaluate the effectiveness of the method of bone transport. The excellent and good rates of bone was $93.97 \%$ (265 of 282), while that of the functional results was $79.43 \%(224$ of 282$)$. These results were similar to other studies ${ }^{15,35,36}$. 
A total of 12 patients suffered refracture either on docking site or regenerate region. Among them, 4 cases were due to early removal of external fixator and 8 cases were due to a fall injury or a car accident after the removal of the protective plaster and all of them achieved union by open reduction and plate fixation.

The present study had several limitations. First, considering its retrospective nature and relatively small sample size, prudent attitude should be adopted regarding the interpretations of our bone and functional outcomes. Second, longer follow-up time is necessary to better evaluate the clinical efficacy. Third, further investigations, especially multi-centered trails with a larger sample size should be conducted to overcome the limitations of our study.

\section{Conclusion}

We present the results of 282 consecutive cases using single or double level bone transport with particular reference to the complications and its related factors. Bone transport is a reliable method for reconstruction of bone defects in the femur and tibia. Particular attention, patient's compliance and experience of the surgeon contribute the satisfactory results.

\section{Abbreviations}

ASAMIA

association for the Study and Application of the Method of Ilizarov criteria; DS:defect size;

DRL

distraction regenerate length;

DT

docking time;

CT

regenerate consolidation time;

EFT

external fixation time;

EFI

external fixation index;

$\mathrm{EF}$

external fixator;

ROM

range of motion

ESR

erythrocyte sedimentation rate

CRP

C-reactive protein

AUC

area under the curve 
ROC

receiver operating characteristic

ULRA

univariate logistic regression analysis;

MLRA

multivariate logistic regression analysis.

\section{Declarations}

\section{Acknowledgements}

Not applicable

\section{Authors' contributions}

YSL: Conducted the study. Collected, analyzed and interpreted the data. Wrote the manuscript.

MY: Designed the study. Interpreted the data. Edited the manuscript.

ZHL: Statistical analyzed and interpreted the data

JLL: Created and statistical analyzed the data

CM: Planned the project. Reviewed the manuscript.

AY: Planned the project. Reviewed the manuscript.

Final approval of the version to be submitted: YSL, MY, ZHL, JLL, CM, AY

\section{Funding}

This work was supported by the grants from National Natural Science Foundation of China (No. 81560357 and 81760397). The funding body was involved in the collection, analysis, and interpretation of data by supporting with salary for the time needed. They were not involved in the design or writing the manuscript.

\section{Availability of data and materials}

The datasets analysed during the current study are available from the corresponding author on reasonable request.

\section{Ethics approval and consent to participate}

This retrospective study was approved by the Ethics Committee of The First Affiliated Hospital of Xinjiang Medical University. Informed consent was waived due to the retrospective nature of this study. 


\section{Consent for publication}

Not applicable

\section{Competing interests}

The authors declare that they have no conflict of interest.

\section{References}

1. Lasanianos NG, Kanakaris NK, Giannoudis PV. Current management of long bone large segmental defects. Orthopaedics and Trauma. 2010;24(2):149-163.

2. Reichert JC, Saifzadeh S, Wullschleger ME, Epari DR, Schutz MA, Duda GN, Schell H, van Griensven $\mathrm{M}$, Redl $\mathrm{H}$, Hutmacher DW. The challenge of establishing preclinical models for segmental bone defect research. BIOMATERIALS. 2009;30(12):2149-2163.

3. Aronson J, Johnson E, Harp JH. Local bone transportation for treatment of intercalary defects by the Ilizarov technique. Biomechanical and clinical considerations. Clin Orthop Relat Res. 1989(243):7179.

4. Osterman AL, Bora FW. Free vascularized bone grafting for large-gap nonunion of long bones. Orthop Clin North Am. 1984;15(1):131-142.

5. Papineau LJ. [Excision-graft with deliberately delayed closing in chronic osteomyelitis]. Nouv Presse Med. 1973;2(41):2753-2755.

6. Rose RE. The llizarov technique in the treatment of tibial bone defects. Case reports and review of the literature. West Indian Med J. 2002;51(4):263-267.

7. Baumgart R, Schuster $B$, Baumgart $T$. [Callus distraction and bone transport in the treatment of bone defects]. ORTHOPADE. 2017;46(8):673-680.

8. Borzunov DY, Balaev PI, Subramanyam KN. Reconstruction by bone transport after resection of benign tumors of tibia: A retrospective study of 38 patients. INDIAN J ORTHOP. 2015;49(5):516-522.

9. Spiegl U, Patzold R, Friederichs J, Hungerer S, Militz M, Buhren V. Clinical course, complication rate and outcome of segmental resection and distraction osteogenesis after chronic tibial osteitis. INJURY. 2013;44(8):1049-1056.

10. Vesely R, Prochazka V. [Callus Distraction in the Treatment of Post-Traumatic Defects of the Femur and Tibia]. Acta Chir Orthop Traumatol Cech. 2016;83(6):388-392.

11. Rohilla R, Siwach K, Devgan A, Singh R, Wadhwani J, Ahmed N. Outcome of distraction osteogenesis by ring fixator in infected, large bone defects of tibia. J Clin Orthop Trauma. 2016;7(Suppl 2):201209.

12. Sadek AF, Laklok MA, Fouly EH, Elshafie M. Two stage reconstruction versus bone transport in management of resistant infected tibial diaphyseal nonunion with a gap. Arch Orthop Trauma Surg. 2016;136(9):1233-1241. 
13. Tetsworth K, Paley D, Sen C, Jaffe M, Maar DC, Glatt V, Hohmann E, Herzenberg JE. Bone transport versus acute shortening for the management of infected tibial non-unions with bone defects. INJURY. 2017;48(10):2276-2284.

14. Yin P, Zhang L, Li T, Zhang L, Wang G, Li J, Liu J, Zhou J, Zhang Q, Tang P. Infected nonunion of tibia and femur treated by bone transport. J ORTHOP SURG RES. 2015;10:49.

15. Aktuglu K, Erol K, Vahabi A. Ilizarov bone transport and treatment of critical-sized tibial bone defects: a narrative review. J Orthop Traumatol. 2019;20(1):22.

16. Girard PJ, Kuhn KM, Bailey JR, Lynott JA, Mazurek MT. Bone transport combined with locking bridge plate fixation for the treatment of tibial segmental defects: a report of 2 cases. J ORTHOP TRAUMA. 2013;27(9):e220-e226.

17. lacobellis $C$, Berizzi A, Aldegheri R. Bone transport using the llizarov method: a review of complications in 100 consecutive cases. Strategies Trauma Limb Reconstr. 2010;5(1):17-22.

18. Krappinger D, Irenberger A, Zegg M, Huber B. Treatment of large posttraumatic tibial bone defects using the llizarov method: a subjective outcome assessment. Arch Orthop Trauma Surg. 2013;133(6):789-795.

19. Liodakis E, Kenawey M, Krettek C, Ettinger M, Jagodzinski M, Hankemeier S. Segmental transports for posttraumatic lower extremity bone defects: are femoral bone transports safer than tibial? Arch Orthop Trauma Surg. 2011;131(2):229-234.

20. Kocaoglu M, Eralp L, Rashid HU, Sen C, Bilsel K. Reconstruction of segmental bone defects due to chronic osteomyelitis with use of an external fixator and an intramedullary nail. J BONE JOINT SURG AM. 2006;88(10):2137-2145.

21. Paley D, Catagni MA, Argnani F, Villa A, Bijnedetti GB, Cattaneo R. Ilizarov Treatment of Tibial Nonunions With Bone Loss. CLIN ORTHOP RELAT R. 1989;\&NA;(241).

22. Borzunov DY. Long bone reconstruction using multilevel lengthening of bone defect fragments. INT ORTHOP. 2012;36(8):1695-1700.

23. Borzunov DY, Chevardin AV. Ilizarov non-free bone plasty for extensive tibial defects. INT ORTHOP. 2013;37(4):709-714.

24. Paley D. Problems, obstacles, and complications of limb lengthening by the llizarov technique. Clin Orthop Relat Res. 1990(250):81-104.

25. Herzenberg JE, Waanders NA. Calculating rate and duration of distraction for deformity correction with the Ilizarov technique. Orthop Clin North Am. 1991;22(4):601-611.

26. Ilizarov GA. Clinical application of the tension-stress effect for limb lengthening. Clin Orthop Relat Res. 1990(250):8-26.

27. Dendrinos GK, Kontos S, Lyritsis E. Use of the llizarov technique for treatment of non-union of the tibia associated with infection. J BONE JOINT SURG AM. 1995;77(6):835-846.

28. Liantis P, Mavrogenis AF, Stavropoulos NA, Kanellopoulos AD, Papagelopoulos PJ, Soucacos PN, Babis GC. Risk factors for and complications of distraction osteogenesis. Eur J Orthop Surg 
Traumatol. 2014;24(5):693-698.

29. Saran N, Hamdy RC. DEXA as a predictor of fixator removal in distraction osteogenesis. Clin Orthop Relat Res. 2008;466(12):2955-2961.

30. Suger G, Fleischmann W, Hartwig E, Kinzl L. [Open segmental bone transport. A therapeutic alternative in post-traumatic and osteitis soft tissue and bone defects]. UNFALLCHIRURG. 1995;98(7):381-385.

31. Wang H, Wei X, Liu P, Fu YH, Wang PF, Cong YX, Zhang BF, Li Z, Lei JL, Zhang K, Zhuang Y. Quality of life and complications at the different stages of bone transport for treatment infected nonunion of the tibia. Medicine (Baltimore). 2017;96(45):e8569.

32. Hantes ME, Malizos KN, Xenakis TA, Beris AE, Mavrodontidis AN, Soucacos PN. Complications in limb-lengthening procedures: a review of 49 cases. Am J Orthop (Belle Mead NJ). 2001;30(6):479483.

33. Noonan KJ, Leyes M, Forriol F, Canadell J. Distraction osteogenesis of the lower extremity with use of monolateral external fixation. A study of two hundred and sixty-one femora and tibiae. J BONE JOINT SURG AM. 1998;80(6):793-806.

34. Paley D, Maar DC. Ilizarov bone transport treatment for tibial defects. J ORTHOP TRAUMA. 2000;14(2):76-85.

35. Farmanullah, Khan MS, Awais SM. Evaluation of management of tibial non-union defect with llizarov fixator. J Ayub Med Coll Abbottabad. 2007;19(3):34-36.

36. Magadum MP, Basavaraj YC, Phaneesha MS, Ramesh LJ. Acute compression and lengthening by the Ilizarov technique for infected nonunion of the tibia with large bone defects. J Orthop Surg (Hong Kong). 2006;14(3):273-279.

\section{Tables}

Table 1 Comparison of the single and double level bone transport group

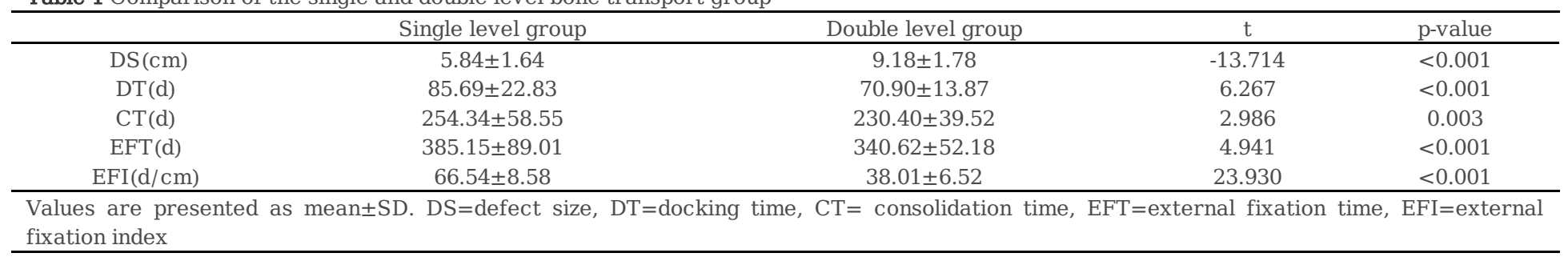


Table 2 Comparison of femur and tibia in different group

\begin{tabular}{|c|c|c|c|c|c|c|c|c|}
\hline & \multicolumn{4}{|c|}{ Single level group } & \multicolumn{4}{|c|}{ Double level group } \\
\hline & Femur & Tibia & $\mathrm{t}$ & $\mathrm{p}$-value & Femur & Tibia & $\mathrm{t}$ & $\mathrm{p}$-value \\
\hline $\mathrm{DS}(\mathrm{cm})$ & $5.75 \pm 1.77$ & $5.87 \pm 1.61$ & -0.437 & 0.663 & $9.39 \pm 1.47$ & $9.11 \pm 1.87$ & 0.520 & 0.605 \\
\hline $\mathrm{DT}(\mathrm{d})$ & $85.54 \pm 24.27$ & $85.73 \pm 22.49$ & -0.050 & 0.960 & $71.64 \pm 12.44$ & $70.67 \pm 14.40$ & 0.227 & 0.821 \\
\hline $\mathrm{CT}(\mathrm{d})$ & $264.02 \pm 67.94$ & $251.66 \pm 55.59$ & 1.296 & 0.196 & $235.29 \pm 36.54$ & $228.91 \pm 40.66$ & 0.525 & 0.602 \\
\hline $\operatorname{EFT}(d)$ & $393.02 \pm 92.35$ & $382.97 \pm 88.21$ & 0.691 & 0.490 & $345.36 \pm 46.39$ & $339.17 \pm 54.22$ & 0.385 & 0.701 \\
\hline $\mathrm{EFI}(\mathrm{d} / \mathrm{cm})$ & $67.72 \pm 11.26$ & $66.22 \pm 7.69$ & 1.073 & 0.285 & $37.19 \pm 4.65$ & $38.26 \pm 7.02$ & -0.536 & 0.594 \\
\hline
\end{tabular}

Table 3 Comparison of single and double level group in different bone

\begin{tabular}{|c|c|c|c|c|c|c|c|c|}
\hline & \multicolumn{4}{|c|}{ Femur } & \multicolumn{4}{|c|}{ Tibia } \\
\hline & SLG & DLG & $\mathrm{t}$ & p-value & SLG & $\overline{D L G}$ & $\mathrm{t}$ & $\mathrm{p}$-value \\
\hline $\mathrm{DS}(\mathrm{cm})$ & $5.75 \pm 1.77$ & $9.39 \pm 1.47$ & -7.021 & $<0.001$ & $5.87 \pm 1.61$ & $9.11 \pm 1.87$ & -11.738 & $<0.001$ \\
\hline $\mathrm{DT}(\mathrm{d})$ & $85.54 \pm 24.27$ & $71.64 \pm 12.44$ & 2.057 & 0.044 & $85.73 \pm 22.49$ & $70.67 \pm 14.4$ & 4.307 & $<0.001$ \\
\hline $\mathrm{CT}(\mathrm{d})$ & $264.02 \pm 67.94$ & $235.29 \pm 36.54$ & -3.396 & 0.001 & $251.66 \pm 55.59$ & $228.91 \pm 40.66$ & 2.595 & 0.010 \\
\hline $\operatorname{EFT}(d)$ & $393.02 \pm 92.35$ & $345.36 \pm 46.39$ & -2.170 & 0.034 & $382.97 \pm 88.21$ & $339.17 \pm 54.2$ & 3.207 & 0.002 \\
\hline $\operatorname{EFI}(\mathrm{d} / \mathrm{cm})$ & $67.72 \pm 11.26$ & $37.19 \pm 4.65$ & 9.856 & $<0.001$ & $66.22 \pm 7.69$ & $38.26 \pm 7.02$ & 22.311 & $<0.001$ \\
\hline
\end{tabular}

Values are presented as mean \pm SD. DS=defect size, DT=docking time, CT= consolidation time, EFT=external fixation time, EFI=external fixation index, $\mathrm{SLG}=$ single level group, $\mathrm{DLG}=$ double level group

Table 4 Results of ASAMI scores

\begin{tabular}{|c|c|c|c|c|c|c|}
\hline & & Excellent & Good & Fair & Poor & Failure \\
\hline \multirow[t]{2}{*}{ ASAMI } & Bone grade & 233 & 32 & 5 & 12 & - \\
\hline & Function grade & 136 & 88 & 47 & 11 & 0 \\
\hline \\
\hline & \multicolumn{6}{|c|}{ Bone results } \\
\hline \multicolumn{7}{|c|}{ Excellent: Union, no infection, deformity $<7^{\circ}$, limb length discrepancy (LLD) $<2.5 \mathrm{~cm}$} \\
\hline \multicolumn{7}{|c|}{ Good: Union plus any two of the following: absence of infection, deformity $<7^{\circ}$, LLD $<2.5 \mathrm{~cm}$. } \\
\hline \multicolumn{7}{|c|}{ Fair: Union plus any one of the following: absence of infection, deformity $<7^{\circ}$, LLD $<2.5 \mathrm{~cm}$. } \\
\hline \multicolumn{7}{|c|}{ Poor: Nonunion/refracture/ union plus infection plus deformity $>7^{\circ}$ plus LLD $>2.5 \mathrm{~cm}$} \\
\hline \multicolumn{7}{|c|}{ Functional results } \\
\hline \multicolumn{7}{|c|}{$\begin{array}{l}\text { Excellent: Active, no limp, minimum stiffness (loss of }<15^{\circ} \mathrm{knee} \text { extension } /<15^{\circ} \text { ankle dorsiflexion) no reflex sympathetic dystrophy (RSD), } \\
\text { insignificant pain. }\end{array}$} \\
\hline \multicolumn{7}{|c|}{ Good: Active, with one or two of the following: limb, stiffness, RSD, significant pain } \\
\hline \multicolumn{7}{|c|}{ Fair: Active, with three or all of the following: limb, stiffness, RSD, significant pain } \\
\hline \multicolumn{7}{|c|}{ Poor: Inactive (unemployment or inability to return to daily activities because of injury) } \\
\hline Failure: & tation & & & & & \\
\hline
\end{tabular}


Table 5 Difficulties related to the bone transport procedure

\begin{tabular}{cccccc}
\hline & \multicolumn{2}{c}{ Single level group } & \multicolumn{2}{c}{ Double level group } & Total \\
\cline { 2 - 5 } & Femur & Tibia & Femur & Tibia & \\
\hline Problem & 41 & 103 & 14 & 31 & 189 \\
Obstacle & 47 & 64 & 18 & 37 & 166 \\
Complication & 68 & 261 & 23 & 54 & 406 \\
\hline
\end{tabular}

\begin{tabular}{lcc}
\multicolumn{3}{l}{ Table 6 Bone transport-related complications } \\
\hline Complications & Minor & Major \\
\hline Deep pin tract infection or pin loosening & 57 & 3 \\
Muscle contractures & 26 & 9 \\
Joint stiffness & 11 & 56 \\
Axial deviation & 87 & 28 \\
Soft tissue incarceration & 63 & 0 \\
Neurological injury & 0 & 0 \\
Vascular injury & 0 & 0 \\
Delayed consolidation & 4 & 7 \\
Delayed union & 9 & 29 \\
Nonunion & 0 & 5 \\
Refracture & 0 & 12 \\
Total & 257 & 149 \\
\hline
\end{tabular}

\section{Figures}

Factors
BMI(2 vs 1)
Bone(T vs F)
Defect size
CT
ET
EFI

Age

Bone

Defect size

Total points

Linear predictor

Risk of pin site problem
$\mathrm{OR}(95 \% \mathrm{Cl})$

$1.89(1.10-3.27)$

$0.24(0.09-0.55)$

$1.19(1.04-1.39)$

$1.01(1.00-1.01)$

$1.00(1.00-1.01)$

$0.98(0.96-1.00)$

1.02 .04 .0

Worse function

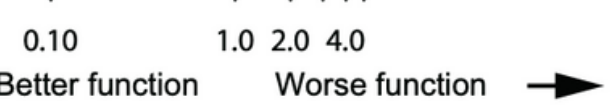

\section{A}
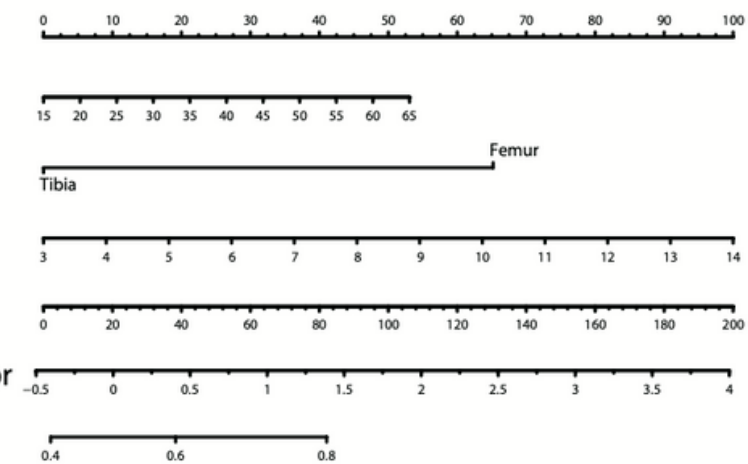

C

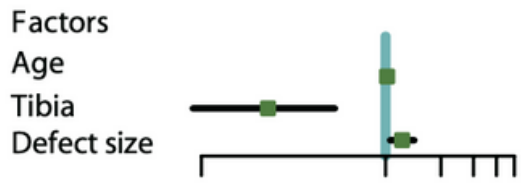

$\mathrm{OR}(95 \% \mathrm{Cl})$

$1.02(1.00-1.05)$

$0.23(0.09-0.53)$

$1.23(1.06-1.43)$

$\square$ Better function Worse function

B

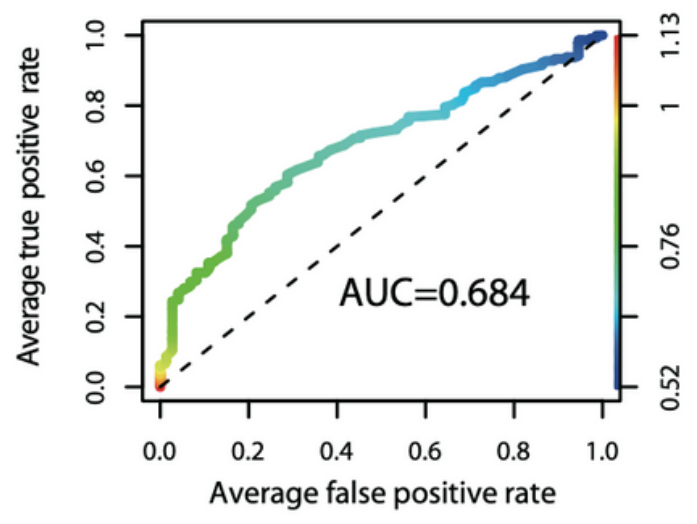

$\mathrm{D}$ 
Analysis of the complication of pin site problem. a Result of ULRA. b Result of MLRA. c Nomogram to predict the probability of pin site problem. $d$ ROC curves for validating the discrimination power of the nomogram. BMI (1= underweight, 2=normal, 3=overweight, 4=obesity), Bone ( $F=f$ emur, $T=$ tibia).

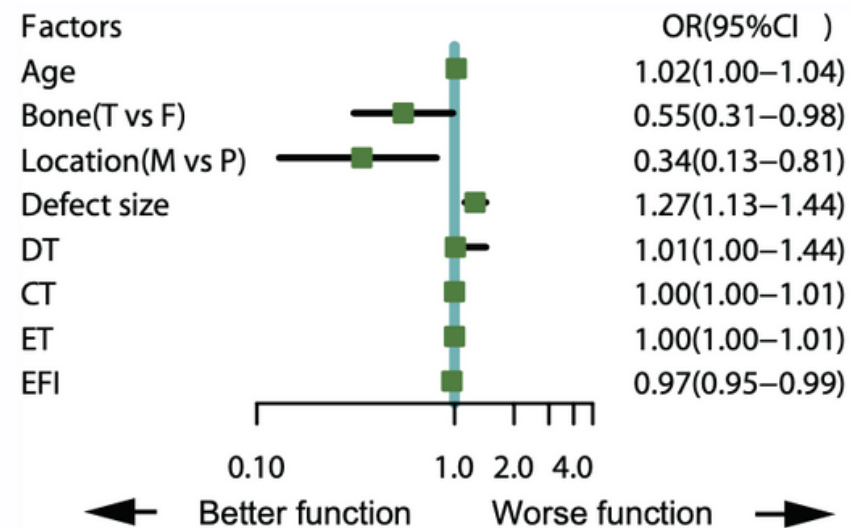

A

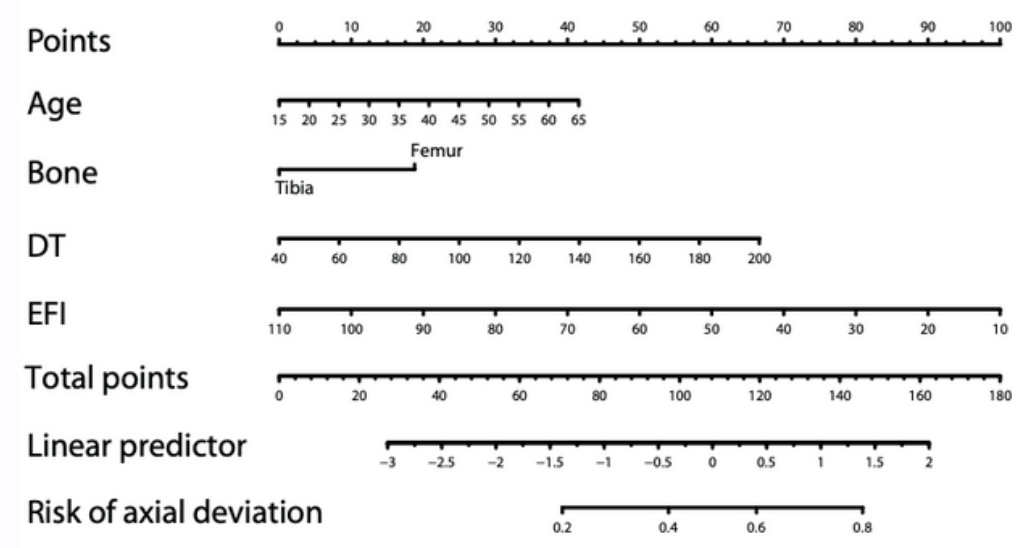

C
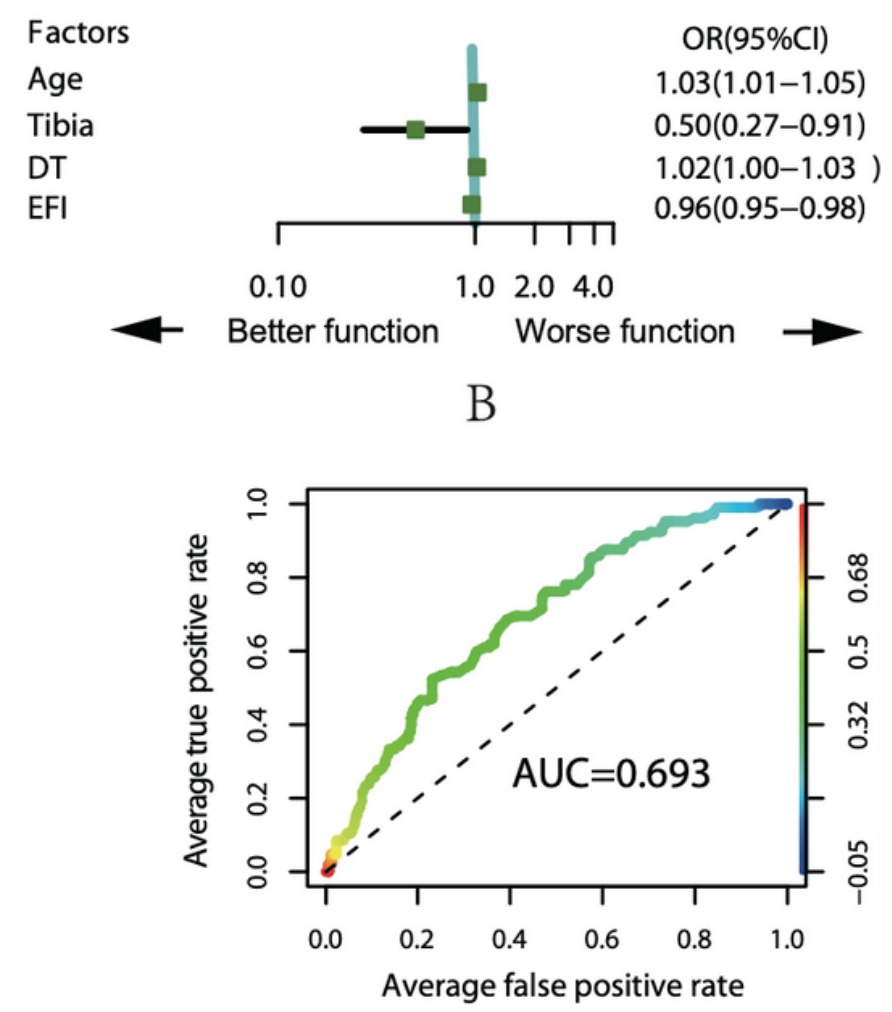

$\mathrm{D}$

\section{Figure 2}

Analysis of the complication of pin site problem. a Result of ULRA. b Result of MLRA. c Nomogram to predict the probability of pin site problem. $d$ ROC curves for validating the discrimination power of the nomogram. Bone ( $\mathrm{F}=$ femur, $\mathrm{T}=$ tibia), Location ( $\mathrm{P}=$ proximal, $\mathrm{M}=$ middle) 

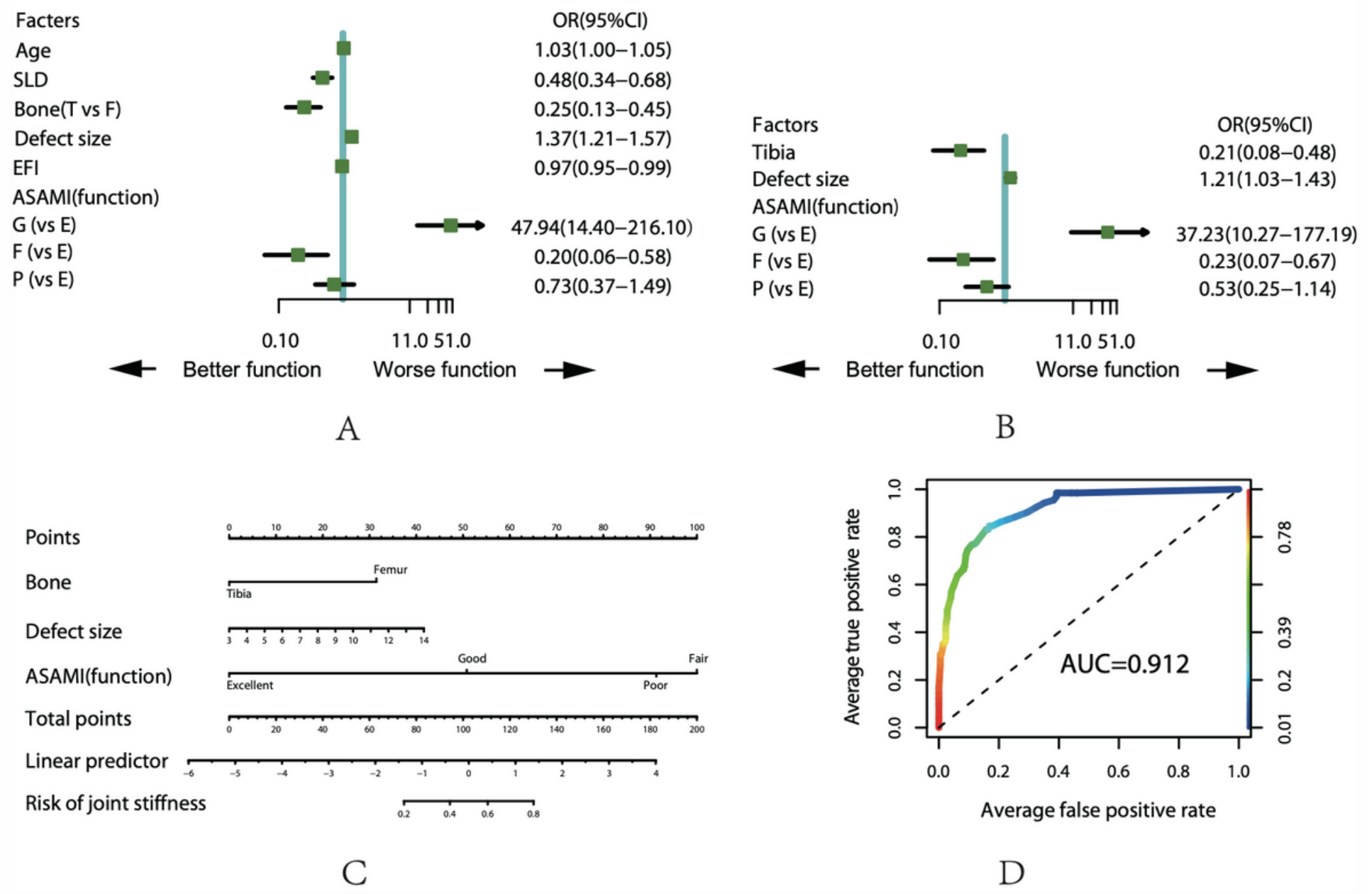

$\mathrm{D}$

\section{Figure 3}

Analysis of the complication of joint stiffness. a Result of ULRA. b Result of MLRA. c Nomogram to predict the probability of pin site problem. $d$ ROC curves for validating the discrimination power of the nomogram. Bone ( $F=$ femur, $T=$ tibia), ASAMI ( $E=$ excellent, $G=$ good, $F=$ fair, $P=$ poor). 
Factors

Defect size

DT

EFI

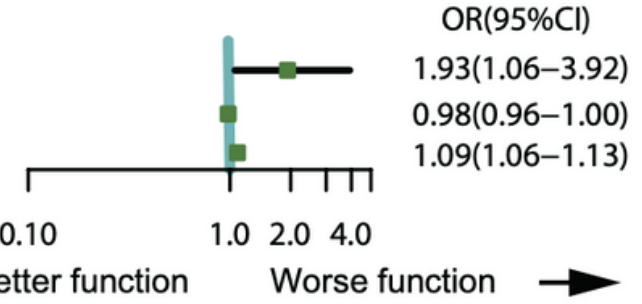

A

Points

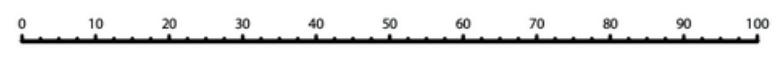

Defect size

DT

EFI

Total points

Linear predictor

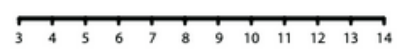

Risk of delayed union of the docking site
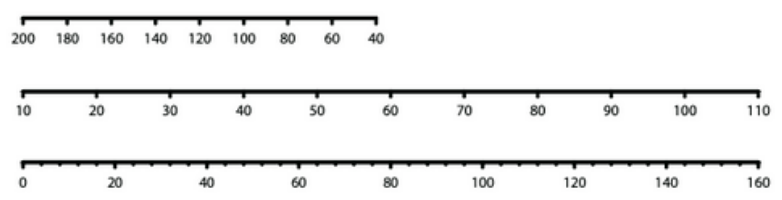

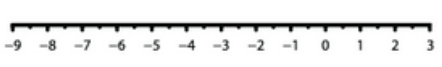

0.20 .40 .60 .8

C
Factors

Defect size

DT

EFI
0.10

$\checkmark$ Better function $\begin{array}{lll}1.0 & 2.0 & 4.0\end{array}$

Worse function

B

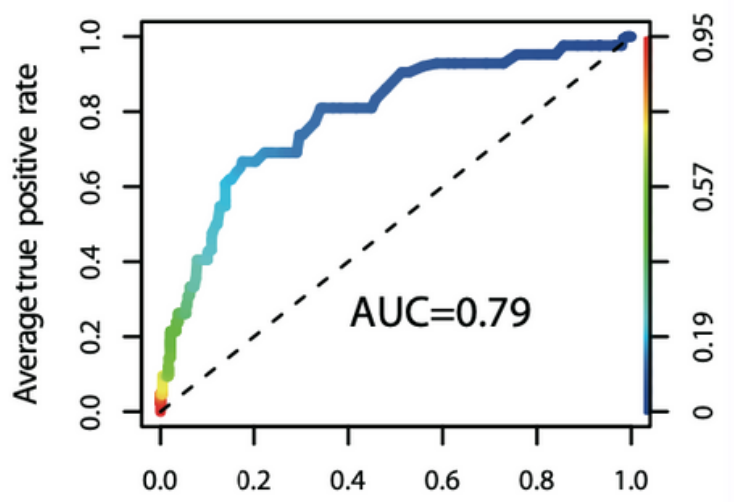

Average false positive rate

$D$

\section{Figure 4}

Analysis of the complication of delayed union of the docking site. a Result of ULRA. b Result of MLRA. c Nomogram to predict the probability of pin site problem. $d$ ROC curves for validating the discrimination power of the nomogram. 


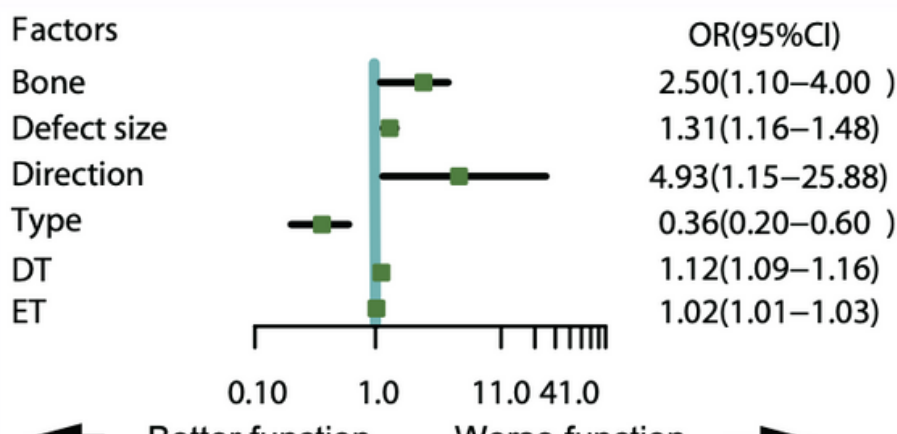

$\longrightarrow$ Better function Worse function $\rightarrow$

A

Points

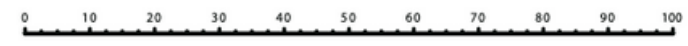

DT

Total points

Linear Predictor

Soft tissue incarceration
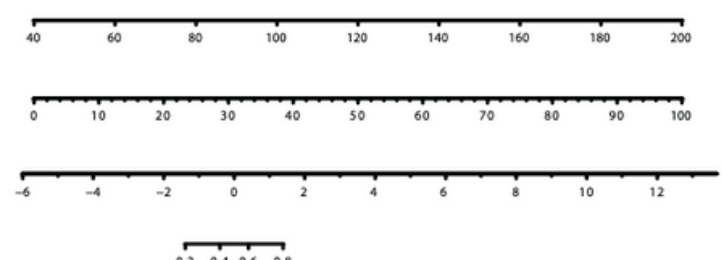

$\longdiv { 0 . 4 0 . 6 0 . 8 }$
Factors

DT
$\mathrm{OR}(95 \% \mathrm{Cl})$

$1.12(1.09-1.15)$

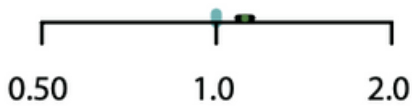

$\longrightarrow$ Better function Worse function $\rightarrow$

B

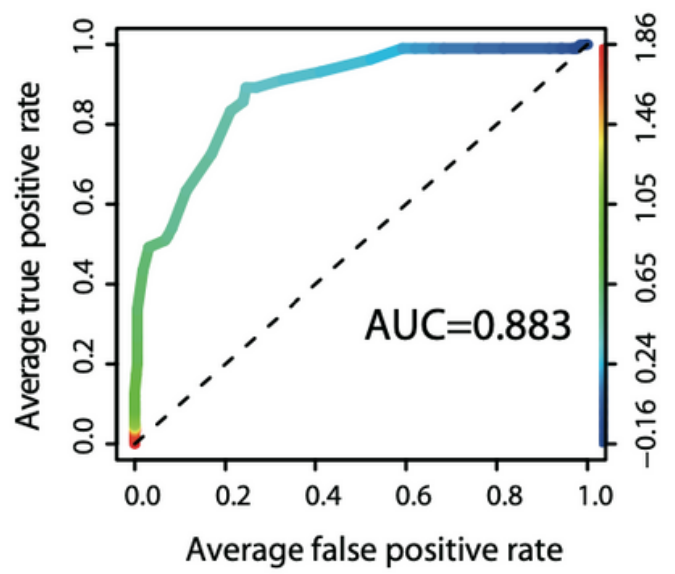

$\mathrm{D}$

\section{Figure 5}

Analysis of the complication of soft tissue incarceration. a Result of ULRA. b Result of MLRA. c Nomogram to predict the probability of pin site problem. $d$ ROC curves for validating the discrimination power of the nomogram. 